\title{
Cardiovascular Effects of Listening to Fast Speech and Normal Speech
}

\author{
Quartey Perez ${ }^{1}$, Blemano David TA' ${ }^{2}$ Odoi Patience ${ }^{3}$ \\ ${ }^{1,2,3}$ Faculty of Health Sciences, Department of Physician Assistantship Studies, Garden City University \\ College, Kenyase, Ashanti Region, Ghana
}

\begin{abstract}
Background: Some previous works on the psychological impact of speech on the cardiovascular system have mainly focused on the speaker as the individual in whom clinical outcomes are being measured. There is limited data on the effects of listening to the fast speech on cardiovascular responses. Aim: The study aimed to comparatively examine blood pressure and heart rate changes upon listening to normal and fast speeches. Method: A total of 88 (22 females and 66 males) normotensive adults were recruited for the study from a university population. All subjects were made to listen to two different 13-minutes audio recordings of normal speech (news commentary) and fast speech (a radio sports presentation). Blood pressure and pulse rate changes were taken at 4-minutes time intervals during listening to the audio recordings. Based on enthusiasm and patronage of the sports program, participants were classified as "Regular" listeners and "Non-regular" listeners. Blood pressure and pulse rate changes were calculated as the mean net area under the curve response, and differences were analyzed with analysis of variance. Results: Systolic, diastolic and pulse rate responses were significantly higher in both the Regular and Non-Regular listener groups during listening to the fast-speech audio presentation as compared to the News Commentary presentation. Conclusion: Although there is limited data, listening to fast speech itself may act as a psychosocial stressor that predisposes to an increased cardiovascular response manifested as higher blood pressure and heart rate.
\end{abstract}

KEYWORDS: Speech-rate; Fast-speech; Normal-speech; Blood pressure; Pulse-rate

\section{INTRODUCTION}

$\mathrm{T}^{\mathrm{s}}$ The suggested relationship between stress and 1 pathophysiological disease processes has come under detailed investigation and is now a growing area of research. [1-8] This comprises of repeated daily exposures to environmental [8] and psychosocial factors. [3,6] Emotional factors that cause psychosocial stress are now part of daily living. Modern life events such as job-related and family problems, financial challenges, social withdrawal, exposure to violence and noise are some factors that can predispose to psychological stress. Currently, the idea that challenging stimuli (stressors) elicit a stress response, which eventually leads not only to psychological adjustments but also to pathophysiological changes is widely accepted. It has, therefore, been suggested that repeated exposure to psychological stress can cause increased blood pressure and lead to hypertension development. $[1,3,5,6,10,11]$ In addition to other possible mechanisms, hyperresponsivity of the sympathetic nervous system, manifested by exaggerated heart rate and blood pressure responses to psychological stimuli, have been identified as an intrinsic characteristic among some individuals with some potential therapeutic overtures. [3,12] The importance of psychosocial factors in the development and expression of cardiovascular disease has been debated because the literature relating psychosocial factors to cardiovascular disease is multidisciplinary, potentially leading to an under-appreciation of the strength of some of the epidemiological and pathophysiological observations that have been reported. [3] Some studies have been done on identification of some "silent stressors". Earlier works [12-15] have reported the effects of fast speaking on

Correspondence: Quartey Perez, Faculty of Health Sciences, Department of Physician Assistantship Studies, Garden City University College, Kenyase, Ashanti Region, Ghana. E-mail: quartey.perez@gcuc.edu.gh

eISSN: 2523-6709

pISSN: 2523-6695

DOI: 10.31878/ijerpp.2020.44.01
(C) Authors; 2020. (CC BY-NC-SA 4.0)

This is an Open Access article which permits unrestricted non-commercial use, provided the original work is properly cited. 
cardiovascular reactivity with limited work on the effects of listening to fast speech. Recently, a common feature in the Ghanaian community is the patronage of "fast-speech" radio sports presentation programs.

\section{Materials ANd Methods}

The Study participants: The study included 1 a total of 88 (22 females and 66 males) from student participants recruited from the university population after explaining the aim and procedures of the study to them and giving their consent. Pregnant individuals or those with current illness, hypertension, or any other known chronic condition were excluded.

Study protocol: Informed consent was received from all participants voluntarily. All procedures were carried out following the Helinski declaration as revised in 2003. No identifying personal data of the participants were used in the publication. After at least 10 minutes of rest, all subjects were made to listen to two different 13-minutes audio recordings on their mobile phones with an earpiece on separate days. The audio recordings were two different "fast speech" presentations (a radio sports presentation program in the local 'Twi' dialect) and "normal speech" presentations (news commentary). Based on the enthusiasm and patronage of the "fast speech" sports program, participants were classified as Regular listeners and Non-regular listeners. Blood pressure and pulse rate were taken at 4-minutes time intervals during listening to the audio presentations with a digital monitor (OmromTM M3 Comfort).

Statistical analysis: Speech rates of the audio recordings were expressed as words per minute. To examine the effects of listening of the audio presentations on blood pressure and pulse rate responses, the net area under the curve which includes both increases and decreases in changes, instead of the incremental area under the curve were used, and the mean of the two separate net area under the curve (AUC) responses were calculated. Differences were compared and analyzed with analysis of variance (ANOVA) of the mean net AUC. Statistical significance among groups was pegged at p-value $<0.05$.

\section{Results}

Seech rates of the audio presentations in the Study: The News commentary presentation had an average of 154 words per minute whiles the Sports presentation had an average of 453 words per minute.

General characteristics of the study population: The general characteristics of the study population are described in table 1 . The study population included a total of 88 (22 females and 66 males) normotensive adult participants in a similar age bracket (mean age of $22.1 \pm$ 2.28 for Regular listeners and $22.5 \pm 1.75$ years for Non-Regular listeners. The mean systolic blood pressure was higher among the Regular listener group. However, there was no significant difference in the mean diastolic blood pressure and pulse rate between the two groups.

Table 1. General Characteristics of the study population.

\begin{tabular}{|l|c|c|c|}
\hline \multicolumn{1}{|c|}{ Parameter } & $\begin{array}{c}\text { Regular } \\
\text { listeners }\end{array}$ & $\begin{array}{c}\text { Non-Regular } \\
\text { listeners }\end{array}$ & p-value \\
\hline $\begin{array}{l}\text { Number } \\
\text { Males }\end{array}$ & 44 & 44 & - \\
Females & 7 & 29 & \\
\hline Age (years) & $22.1 \pm 2.28$ & $22.5 \pm 1.75$ & $0.321(\mathrm{~ns})$ \\
\hline $\begin{array}{l}\text { Systolic BP } \\
\text { (mmHg) }\end{array}$ & $109.5 \pm 8.9$ & $106 \pm 7.84$ & 0.036 \\
\hline $\begin{array}{l}\text { Diastolic BP } \\
\text { (mmHg) }\end{array}$ & $72.5 \pm 3.29$ & $72.4 \pm 3.16$ & $0.844(\mathrm{~ns})$ \\
\hline $\begin{array}{l}\text { Pulse rate } \\
\text { (bpm) }\end{array}$ & $74.2 \pm 12.1$ & $78.4 \pm 11.3$ & $0.096(\mathrm{~ns})$ \\
\hline
\end{tabular}

Results are expressed as means \pm standard deviation. BP: blood pressure. Bpm: beats per minute. ns: non-significant p-value

\section{Distribution of cardiovascular responses}

The mean net area under the curve responses of systolic blood pressure, diastolic blood pressure and pulse rate in the subject groups, are illustrated in the ANOVA results in tables 2 and 3 . The systolic and diastolic blood pressure AUC responses were significantly higher in both the Regular and Non-Regular listeners during listening to the fast-speech audio presentation as compared to the News Commentary presentation. Additionally, significantly raised pulse rate was observed among the Regular listeners during listening to the fast-speech audio presentation as compared to the News Commentary presentation. The multiple comparison analysis showed no significant differences in the mean cardiovascular responses between the Regular and Non-Regular listener groups during listening to the fast-speech audio presentation.

Table 2. ANOVA distribution of mean net systolic, diastolic, blood pressure area under the curve.

\begin{tabular}{|l|c|c|c|l|l|}
\hline \multicolumn{1}{|c|}{$\begin{array}{c}\text { Para- } \\
\text { meter }\end{array}$} & $\begin{array}{c}\text { News } \\
\text { comme- } \\
\text { ntary }\end{array}$ & $\begin{array}{c}\text { Regular } \\
\text { listeners }\end{array}$ & $\begin{array}{c}\text { Non- } \\
\text { Regular } \\
\text { listeners }\end{array}$ & $\mathrm{F}$ & $\mathrm{p}$-value \\
\hline $\begin{array}{l}\text { Systolic BP } \\
\text { (mmHg) }\end{array}$ & $7.42 \pm 4.5$ & $17.2 \pm 7.4$ & $16.5 \pm 5.1$ & 65.2 & $<0.0001$ \\
\hline $\begin{array}{l}\text { Diastolic BP } \\
\text { (mmHg) }\end{array}$ & $4.13 \pm 4.4$ & $7.73 \pm 4.3$ & $6.6 \pm 3.66$ & 12.1 & $<0.0001$ \\
\hline $\begin{array}{l}\text { Pulse rate } \\
\text { (bpm) }\end{array}$ & $4.08 \pm 4.2$ & $8.7 \pm 6.2$ & $6.26 \pm 5.2$ & 12.8 & $<0.0001$ \\
\hline
\end{tabular}

Results are expressed as means \pm standard deviation.

BP: blood pressure. Bpm: beats per minute 
Table 3: Post-hoc multiple comparisons of the mean net area under the curve between groups.

\begin{tabular}{|c|c|c|c|c|}
\hline Para- & \multicolumn{2}{|c|}{ Groups } & Adjusted & \multirow[t]{2}{*}{$95 \% \mathrm{CI}$} \\
\hline \multicolumn{2}{|r|}{ Regular } & \multicolumn{2}{|c|}{ News commentary } & \\
\hline Systolic BP & $17.2 \pm 7.4$ & $7.42 \pm 4.46$ & $<0.0001^{\star}$ & -12.2 to -7.4 \\
\hline Diastolic BP & $7.73 \pm 4.34$ & $4.13 \pm 4.41$ & $<0.0001^{*}$ & -4.3 to -0.6 \\
\hline Pulse rate & $8.71 \pm 6.2$ & $4.08 \pm 4.21$ & $<0.0001^{*}$ & -6.8 to -2.4 \\
\hline \multicolumn{2}{|c|}{ Non-Regular listeners } & \multicolumn{3}{|c|}{ News commentary } \\
\hline Systolic BP & $16.5 \pm 5.10$ & $7.42 \pm 4.46$ & $0.0001^{\star}$ & -11.5 to -6.7 \\
\hline Diastolic BP & $6.55 \pm 3.66$ & $4.13 \pm 4.41$ & $0.006^{*}$ & -4.3 to -0.6 \\
\hline Pulse rate & $6.26 \pm 5.16$ & $4.08 \pm 4.21$ & 0.052 & -4.4 to 4.9 \\
\hline \multicolumn{2}{|c|}{ Regular listeners } & \multicolumn{2}{|c|}{ Regular listeners } & \\
\hline Systolic BP & $17.2 \pm 7.40$ & $16.5 \pm 5.10$ & 0.821 & -2.1 to 3.5 \\
\hline Diastolic BP & $7.73 \pm 4.34$ & $6.55 \pm 3.66$ & 0.390 & -0.9 to 3.3 \\
\hline Pulse rate & $8.71 \pm 6.20$ & $6.26 \pm 5.16$ & 0.058 & -0.06 to 4.9 \\
\hline
\end{tabular}

Results are expressed as means \pm SD. *significant

$\mathrm{BP}$ in $\mathrm{mm} / \mathrm{Hg}$, Pulse rate:bpm

\section{Discussion}

$\Delta$ variety of evidence shows that stress Acontributes to a more sustained elevation of blood pressure, as well as to the triggering and aggravation of cardiovascular pathology. [1,3] It may either serve as a risk factor, [5] induce blood pressure spikes, or increase already elevated blood pressure. $[3,6,7]$ Some works have been done on the cardiovascular effects of listening. For example, the acute effects of exposure to noise on systolic and diastolic blood pressure, and heart rate have been assessed among 46 workers in an auto assembly plant [13]. Workers wore ambulatory blood pressure monitors and personal noise dosimeters during one work shift. After adjustment for covariates of cardiovascular function, systolic and diastolic blood pressure, along with pulse rate, were shown to be significantly positively associated with noise exposure. The study concluded that reducing acute noise exposure reduces cardiovascular stress. However, previous works on the psychosocial impact of speech on the cardiovascular system have mainly focused on the speaker as the individual in whom clinical outcomes are being measured. Smith et al. [15] examined the effects of speaking into a dialogue box under normal and frustration conditions with the use of continuous spontaneous speech. The authors also explored the effects of speaking on pulse rate. Their results revealed that regardless of the individual user's emotional state, pulse rate tends to increase during speaking into the dialogue system right and that this effect is greater when the subject is expressing frustration. Their results also showed that the user's pulse rate does not resolve to the pre-speaking levels quickly after the frustrated speech component as it does after the neutral speech. Lynch et al. [16] showed a positive relationship between talking and an increase in blood pressure and pulse rate in both normotensive and hypertensive individuals. Their results showed a significant positive correlation between the level of resting pressure and the magnitude of increase in pressure while talking, pointing to the suggestion of an important link between communication and blood pressure control that has previously been overlooked. They, therefore, suggested a new conceptual approach to the understanding and treatment of hypertension inclusive of reduction of psychosocial stress. The effects of two rates of speech on blood pressure and heart rate were measured in 30 normotensive individuals by Friedmann et al. [17] They reported that verbalization was linked to rapid and significant rises in blood pressure. Faster rates of speaking were also associated with greater increases in blood pressure. Siegman et al. [18] reported that increasing speech rate and loudness both caused a minimal increase in cardiovascular reactivity whiles reduction in speech rate and loudness was associated with a significant reduction in cardiovascular response. The results of the current study showed that listening to the fast speech itself may serve as an acute psychosocial stressor that causes an increased cardiovascular reactivity manifested as higher blood pressure and pulse. A combination of pathophysiological and epidemiological studies has established that both acute and chronic forms of psychosocial stress contribute to the pathogenesis of cardiovascular diseases. The concept of identifying, studying and integrating psychosocial interventions designed for their avoidance as general protection from their deleterious effects may prove potentially beneficial in high-risk individuals. However, evidence to support this hypothesis has been potentially limited due to lack of adequate clinical investigation [3]. The study has important strengths. Firstly, the study used an experimental design involving an equal number of both groups (Regular and Non-Regular listeners). Secondly, all exposures and outcome measurements were conducted on separate days. Thirdly, the outcome effects were measured at specific time-points using the area under the curve analysis. The calculated area under the curve was the net area under the curve, instead of just the total area under the curve, to include peaks that go below the baseline. This gives a description of the overall outcome effect during the exposure. Previous studies typically measured outcome effects only at end-point of the exposure. [13-14] Despite these strengths, a key limitation of the study was that only normotensive healthy individuals were used and therefore, the effects may not be generalized in subjects with established cardiovascular conditions.

\section{Conclusion}

Most previous works on the psychosocial impact of speech on the cardiovascular system have mainly focused on the speaker as the individual 
in whom clinical outcomes are being measured. There is limited data on the effects of listening to the fast speech on cardiovascular response. This current study concludes that listening to the fast speech itself promotes an increased cardiovascular response seen as higher blood pressure and heart rate. Replication of this study using a more significant number of subjects, monitored for several days in different settings is recommended.

Acknowledgement: The authors are very grateful to all the study participants for their voluntary participation.

Source of Support: The study was self-funded

\section{Conflict of Interest: None Declared}

\section{ReFerenCes}

1. Consoli SM. Stress and the cardiovascular system. Encephale. 1993;1:163-70

2. McEwen BS. Protective and damaging effects of stress mediators. New England Journal of Medicine.1998; 338:171-9

3. Rozanski A, Blumenthal JA, Kaplan J. Impact of Psychological Factors on the Pathogenesis of Cardiovascular Disease and Implications for Therapy. Circulation. 1999; 99: 2192-217

4. Esch T. Health in Stress: Change in the Stress Concept and its Significance for Prevention, Health and Lifestyle. Gesundheitswesen. 2002;64:73-81

5. Esch T, Stefano GB, Fricchione GL, Benson H. Stress in cardiovascular diseases. Med Sci Monit. 2002; 8(5): RA93-101

6. Everson-Rose SA, Lewis TT. Psychosocial Factors and Cardiovascular disease. Review of Public Health. 2005;26: 469-500

7. Gasperin D, Netuveli G, Dias-da-Costa J.S, Pattussi M.P. Effect of psychological stress on blood pressure increase: a meta-analysis of cohort studies Cad. Saúde Pública, Rio de Janeiro. 2009;25(4):715-26

8. Munzel T and Daiber A. Environmental Stressors and Their Impact on Health and Disease with Focus on Oxidative Stress. Antioxid Redox Signal. 2018;20:28(9):735-40

9. Selye H. The Evolution of the Stress Concept. American Scientist.1973;61:692-99.

10. McEwen BS. Physiology and neurobiology of stress and adaptation: central role of the brain. Physiol Rev. 2007;87:873-904

11. Bhelkar S, Deshpande S, Mankar S, Hiwarkar P. Association between Stress and Hypertension among Adults More Than 30 Years: A Case-Control Study. Natl J Community Med. 2018;9(6):430-33

12. Linden W, Moseley JV. The efficacy of behavioral treatments for hypertension. Appl Psychophysiol Biofeedback. 2006; 31:51-63

13. Lusk SL, Gillespie B, Hagerty BM, Ziemba RA. Acute effects of noise on blood pressure and heart rate. Arch Environ Health. 2004; 59(8):392-9

14. Saguna S, Deepika K. The effects of music on pulse rate and blood pressure in health young adults. Int J Res Med Sci. 2017; 5:5268-72

15. Smith J, Tsiatas E, Shriberg A, Kathol A, Willoughby A, de Zambotti M. "Analysis and prediction of heart rate using speech features from natural speech" in Proc. ICASSP. 2017; 98993

16. Lynch JJ, Thomas SA, Long JM, Malinow KL, Friedmann E, Katcher AH. Blood pressure changes while talking. Isr J Med Sci. 1982;18(5):575-9

17. Friedmann E, Thomas SA, Kulick-Ciuffo D, Lynch JJ, Suginohara M. The effects of normal and rapid speech on blood pressure. Psychosom Med. 1982; 44(6):545-53

18. Siegman AW, Dembroski T.M, Crump D. Speech rate, loudness, and cardiovascular reactivity. Journal of Behavioral Medicine. 1992;15:519-39 